\title{
EN EL TALLER DE WALTER BENJAMIN
}

\author{
ÁNGEL MARÍA SOPÓ
}

Universidad Santo Tomás, Colombia

(c) (i) 


\title{
EN EL TALLER DE WALTER BENJAMIN
}

Resumen: el texto plantea algunos elementos teóricos relativos al pensamiento y obra de Walter Benjamin. Al respecto se puede hablar de la sombra, de la cita, del libro, en fin, de la colección. Somos atraídos por ella. De esto se trata aquí. También del método en el texto de «Los colores», de su lectura y hermenéutica. Esto no es más que una corta introducción a sus materiales, métodos e instrumentos ópticos.

Palabras clave: Walter Benjamin, hermenéutica, método arqueológico, fragmento, cita.

\section{IN THE WALTER BENJAMIN'S WORKSHOP}

\begin{abstract}
This paper addresses some theoretical elements related to Walter Benjamin's thought and work. In this respect we can speak about the shadow, the quote, the book and, at last, the collection. We are attracted to it. Such is the subject of this paper. We will also deal with the method in the text "The colors", with its reading and its hermeneutics. This is nothing more than a short introduction to his materials, methods and optical instruments
\end{abstract}

Keywords: Walter Benjamin, hermeneutic, archaeological method, fragment, quote.

Fecha de recepción: octubre 14 de 2016 Fecha de aceptación: noviembre 28 de 2016

Forma de citar (APA): Sopó, A. (2017). En el taller de Walter Benjamin. Revista Filosofía UIS. 16 (1), doi: http://dx.doi.org/10.18273/revfil.v16n1-2017008

Forma de citar (Harvard): Sopó, A. (2017). En el taller de Walter Benjamin. Revista Filosofía UIS. 16 (1), 167-178.

Ángel María Sopó: colombiano. Doctor en Educación, Universidad Pedagógica Nacional. Profesor Universidad Santo Tomás, Bogotá-Colombia.

Correo electrónico: amasopo@gmail.com

$\overline{\text { * Artículo de reflexión }}$ 


\section{EN EL TALLER DE WALTER BENJAMIN}

"Por el bien de mi taller [...]" (Benjamin, 1998, p. 39).

\section{Introducción}

El texto como taller, Nuevos manuscritos, nuevos libros, nuevos materiales. Citas, pasajes y fragmentos; cortes, superficies, suelos y articulaciones en el tejido. Metáforas, giros, colgaduras al viento, al sol y al agua de tintas en papeles especiales. Ahora los fragmentos tienen nombre después de muchas búsquedas, extravíos y batallas. Cada fragmento tiene una historia perdida en los pequeños parajes en que se consume su existencia, ora en ciudades, bibliotecas, molinos, veleros, en el ir y venir de la correspondencia. En suma, un trozo de vida plasmado en la memoria del "árbol del esmero" (Marx, 2010, p. 24) lleno con los colores de "pequeños fragmentos" (Scholem, 2007, p. 54); con los relámpagos que de repente aparecen en el cielo, mostrando en su fogonazo los "círculos concéntricos" (Adorno y Benjamin, 1998, p. 107) en que se desenvuelve su obra; con los "puntos luminosos" (Benjamin, 2004, p. 937) que todavía hay que traducir. Entonces aparecen las preguntas inconcebibles e inesperadas: ¿qué es una cartilla? como motivo para exponer la relación entre el niño y las letras o la sorpresiva pregunta: "iqué es el latón?" (Benjamin, 2015, p. 98). Y, con las cuestiones, los colores, los libros, el pupitre, el árbol del esmero, la confitura, y quizá, una que otra frase célebre que un atento estudiante puede aprender como una constelación. Entonces, la pregunta no es cómo entrar en este mundo, sino cómo salir de él, pues, somos lo que dicen sus fragmentos, sus andanzas y recuerdos. Al iniciar abril de 1935, le escribe Benjamin a Adorno, estas líneas con las que termino: "al pensar en una carta me sentía igual que el capitán de un velero obligado a tomar su cuaderno de bitácora estando el mar en plena calma. ¿Qué podría anotar en él?" (Adorno y Benjamin, 1998, p. 87). 


\section{En el taller de Benjamin}

Lo siguiente. Tenemos la obra de Walter Benjamin. En ella, la tarea para la casa: buscar y comprender el texto, encontrar y proponer un epígrafe, hacer una exposición del texto según el epígrafe. Hacer la tarea.

En hermenéutica no hay más que una tarea: comprender "las cosas mismas" del texto (Gadamer, 1992, p. 65). Dicho de otra manera: considerar los textos que vienen a nosotros en forma de escritos, ensayos, diálogos, cartapacios, fragmentos, citas, aforismos, constelaciones y todas las demás formas de escritura en que se proponen pensamientos, diálogos e interpelaciones. Este principio fenomenológico de ir «a las cosas mismas»es, para el filólogo, el texto mismo.

Para entender cómo son las cosas y en qué dificultades nos metemos cuando tratamos de comprender la experiencia hermenéutica, sobra decir que el siguiente pensamiento de Benjamin cifra una lección de hermenéutica en relación a una teoría del sentido:

Aunque no vamos a hablar de esto por ahora, no olvidaremos, en lo que sigue, que los niños pueden encontrar en los libros, como en todo, cosas muy diferentes de las que encuentran los adultos (2015, p. 275).

Para no asustarnos, eso quiere decir que el texto no tiene un solo sentido. En consecuencia, como decía Nietzsche (1992, p. 87), no existe única interpretación, pues, cada uno lee según su interés, experiencia, perspectiva y entendimiento.

Hablamos de Walter Benjamin. Es el pensador de la cita, del fragmento, de la línea, de la constelación. En una línea, una cita; en la cita, un fragmento de obra, en la obra, el mundo con sus colecciones de ciudades, pasajes, libros y bibliotecas, máquinas, artefactos, muñecas y juguetes. Todo, para el niño, bajo la tapa del pupitre. El mundo en una colección de libros de literatura infantil. El mundo es desembalado del mismo modo como Benjamin desempacaba su biblioteca porque algo tiene que ver la colección con lo que hacemos, las citas con lo que pensamos, los trozos que arrancamos de la historia con lo que somos en el presente. Benjamin no tiene más pretensión que comprender el presente mediante una lectura de París, capital del siglo XIX, recogiendo la larga tradición de Platón de entender el tiempo mediante el pensamiento. Por eso, él repasa también nuestra historia y nuestra vida en un friso, en un pasaje, en aquellas "barras de tiza verdes, amarillas o rojizas" (Benjamin, 2015, p. 176) que encontramos cuando leemos a Hegel, Nietzsche, Husserl, Wittgenstein.

Él cuenta una historia, la de Herodoto. La de aquél que realiza un viaje para tener algo que contar. Es, por eso, "alguien que viene de muy lejos" con su cuento (Benjamin, 2010, pp. 61-69). En cada historia, una cita, una fábula, un sueño y 
algo más: una anécdota. Todo lo puede relatar, enviar y coleccionar; menos el "más" porque en Benjamin nunca sobra un "más". Es la flor que producirá el fruto.

Buscar la cita; encontrar la anécdota, por ejemplo: "El médico encontró que yo era miope. Y me recetó no sólo unas gafas, sino también un pupitre" (Benjamin, 1982, p. 95). No se trata de ensamblar la cita en el todo. Eso queda pendiente para el momento de la articulación. Sino de topar la cita apropiada que asuma la función de epígrafe. En la cita un mundo: el mundo incómodo y difícil de Walter Benjamin en Berlín, París, Ibiza, Nevers, en Port Bou. La cuestión es darnos cuenta que epígrafe y cita dependen del tema. Lo mismo que el texto.

A partir del tema establecer el epígrafe que, en contadas líneas, determine la disposición y concentre la atención sobre el "punto medio" (Dilthey en Gadamer, 1992, p. 63). Ya entonces la cosa mostrará el engarce entre tema, título y epígrafe. De los cientos de citas y comentarios habrá que notar la dirección del engarce en relación entre mediación y extremos para señalar hacia dónde tiende el vector que indica una dirección de búsqueda de sentido. Así, el epígrafe es resumen, introducción, articulación de las partes entre sí en la debida correspondencia y conclusión.

De repente, por el torbellino de la comprensión, la cita se vuelve epígrafe. El epígrafe se ha tomado del laberinto de citas y palabras. Sin palabra no hay citas y sin citas, no hay historias ni recuerdos. El aula de la memoria desaparece.

¿Recuerdas la cita de Herodoto? En verdad, ¿no la recuerdas? Herodoto se fue de viaje por Egipto y por medio mundo conocido para tener qué contar. Lo mismo fue Benjamin, un viajero incansable buscando una cita, coleccionándola, cuaderno tras cuaderno, para tener qué decir acerca del transcurrir de su sombra.

Él es el viajero y su sombra. Su sombra es la cita, el fragmento, la noticia que cuenta sacada de la sombra. Lo mejor de Benjamin es que la conserva con su sol. ¿Hay un retrato de Gisèle Freund de Benjamin con su sombra? Sí, la sombra se esconde en los extractos que lo acompañaron en la Bibliothèque National de Paris. Tenemos, así, el retrato que cada uno se hace de su sombra. Todavía está allí, el papelito, donde escribimos una cita para tener su sombra, sin saberlo. La llamó, La despensa.

Cuál un amante, por la noche, mi mano penetraba por la rendija apenas abierta de la despensa. Una vez que se había orientado, palpaba el azúcar o las almendras, pasas o confituras. Y como el amante abraza a la amada antes de besarla, el sentido del tacto se daba cita con esas cosas, antes de que la boca probara su dulzor. iCuán lisonjeros se entregaban la miel, los montones de pasas, incluso el arroz! iCuánta pasión había en el encuentro, una vez que se escapaban de la cuchara! Agradecida e impetuosa, como 
la muchacha a la que se acaba de raptar de la casa de sus padres, la mermelada de fresa se dejaba probar sin panecillos, desnuda bajo los cielos de Dios, e incluso la mantequilla respondía con cariño al atrevimiento del pretendiente que penetraba en su cuarto de soltera. La mano del joven don Juan pronto había entrado en todos los ángulos y rincones, derramando detrás de sí capas y montones chorreantes: la virginidad que se renueva sin lamentaciones (1982, p. 42).

\section{La cita}

Llevamos su sombra en el morral como él dejó la suya en el Archivo. La llevo a clase. No se escapa y va pasando lentamente de mano en mano. En algunos, fluye y esconde; en otros, permanece como una cita cualquiera en el cuaderno. Pero, los interesados la conservan sombreándola con sus lápices de colores y sus gises y pasan por esa sombra muchas veces durante el día como si fuese su liturgia.

Él se topa con su «sombra» a cada rato; Husserl se encuentra con su «niebla vacía» y Wittgenstein con su "bruma"; Gadamer con un "muro de oscuridades" y Tales cae en su «pozo». Benjamin, se encontró con sus citas de cientos de colores, las coleccionó en Calle de dirección única, en Infancia en Berlín hacia 1900, en El libro de los pasajes y Correspondencias. Las colgó allí donde fue necesario: en un fragmento, en un artículo periodístico, en una emisión por radio, en sus Tesis y, por un cigarro, en el tablero profesoral de Nevers. Desde entonces siempre ha estado ahí esperando el ladrón en la noche, a pesar de las maquinaciones y del zarpazo de Adorno contra Benjamin

La cita se recorre por sí misma dejando una huella: en una rama que cruje a nuestro paso, en el árbol que llama, en la estela del barco camino a Dinamarca. La tuerca rota gira ronca, el monstruo y el espanto lo mismo que los peces dorados en el cuaderno de notas. Los juguetes y la casa de las muñecas. Las prostitutas en los umbrales en el «árbol del esmero». Todo abre un ojo hasta la oficina de la esquina.

Algo tiene que ver la biblioteca con la cita. Al recorrer la selva virgen, recoge el explorador sus hojas, sus flores y sus frutos como el lector sigiloso tras su presa. Tanto el uno como el otro, salen de caza del «último dinosaurio de Europa», el capitalismo, y vuelven blandiendo la terrible hacha ensangrentada de la razón; ambos tienen la suya que habla de experiencia, arte, técnica y, hasta de una ciencia y una filosofía de la caza, con instrumentos, escondrijos y parajes. Pero en este aprender a leer el cuento, el «monstruo» también nos tiene en mira y parece saber nuestra intención, e igual que alguno de nosotros, hila fino en el canto de las expectativas (Benjamin, 2004, pp. 289; $460 ; 554)$.

A nosotros corresponde seguir la huella en su dirección. Viene la meditación. Inicia con la Tesis $X$ sobre la regla conventual cuyo objeto es alejar del mundo y sus afanes. Así, la cita ejerce su carácter destructivo al arrebatar al paseante ocioso su convicción. 
Desde el otro lado, se dispara contra los relojes de las torres y se suprime la continuidad para imponer ruptura. El reloj se descarga en mil pedazos y el tiempo carece de homogeneidad. Tan radical fenomenología, «en primera persona», la ejerce la cita.

De modo que no es quitar ni pulir como en el taller de carpintería del padre de Heidegger, sino el de empezar de nuevo en el polvo del advenir luminoso del tiempo, cuando se ejerce el oficio de sacudir, desenterrar y limpiar con picos, palas y cepillos (Buck-Morss, 1995, p. 112) las capas que ocultan el significado.

Benjamin sabe del poder de la cita, la busca, la espera, la encuentra, copia y comprende. No hay cita que no tenga tiempo y lugar. Es condición de su existencia. Escondida o no, está a flor de piel. A ella se la reconoce bajo el signo de la novedad como cielo nuevo en una tierra nueva que destella su esplendor.

Habrá que buscar la huella y cavar para hallar el tesoro que una vez el padre escondió en su viña. Cavaron por doquier. No encontraron, pero se comprendió que la riqueza no está en el oro, sino en la laboriosidad (Benjamin, 2007, p. 217). Habrá entonces que topar el campo de exploración; limpiar, excavar y urbanizar con el "hacha afilada de la razón".

Urbanizar áreas en las que hasta ahora sólo crecía, silvestre, la locura. Avanzar con el hacha afilada de la razón y sin mirar ni a derecha ni a izquierda, para no sucumbir al espanto que nos atrae desde lo más profundo de la selva. Toda la tierra ha tenido que ser urbanizada por la razón, ser limpiada de los arbustos de la locura y de los mitos. Esto es lo que hay que hacer aquí con el siglo XIX (Benjamin, 2012, p. 19).

En este sentido, propongo como epígrafe la siguiente cita:

Este escrito que trata de los pasajes de París fue comenzado bajo un libre cielo azul sin nubes que se abovedaba sobre el follaje y que, sin embargo, estaba cubierto por millones de hojas, en que susurraban la fresca brisa del esmero, el pesado aliento del investigador, el embate del celo joven y el airecillo perezoso de la curiosidad, con polvo de cientos de miles de años. Pues el cielo de estío pintado que mira hacia abajo desde las arcadas en la sala de trabajo de la Biblioteca Nacional de París, ha extendido su cubierta soñadora y sin luz sobre [este escrito] (Benjamin, 2009, p. 88).

En ella topa, en su dirección: el lugar, la sombra, el «árbol del esmero» que retorna en cada cita que conserva «el polvo de cientos de miles de años» ante el maravilloso asiento y mesa de trabajo que destina el investigador para la lucha que le espera. Al frente, la hoja en blanco. 
Benjamin cita su ejercicio de investigador haciendo posible reconstruir su objeto de estudio y métodos de trabajo yendo a sus raíces y tallitos y a las hojas del «árbol del esmero» junto a sus afanes, previsiones y discusiones. Un desafío en medio de las dificultades económicas y la persecución política.

Tenemos un lugar: el taller de trabajo de Walter Benjamin; una cita tomada del "árbol del esmero" cuyas raíces están en su corazón y sus hojas en los archivos de los amigos, según escribió alguna vez a Gershom Scholem; un "terreno virgen", "ámbito jamás hollado". En el fondo, un punto de partida que se marca por un oír constante: "La necesidad de escuchar agudamente, durante muchos años, a cada cita, a cada pasajera mención de un libro" (Benjamin, 2009, p. 107), como la que sigue: "Estudiante y cazador. El texto es un bosque en el que el lector es el cazador. Crujiendo entre las ramas — la idea, la caza esquiva, la cita - una pieza del retablo. (No todo lector da con la idea.)." (2012, p. 111).

Recuerdo que, en Calle de dirección única, menciona su taller de trabajo en que se traza el "círculo mágico del fragmento» de la hermenéutica contenido en el «árbol del esmero": "En las áreas de la que nos ocupamos, la comprensión sólo se produce en forma de relámpagos. El texto es el largo trueno que los sigue"(15)

Imagino ahora a Hegel asustando a los niños y a Benjamin mirándonos de reojo desde su puesto de trabajo en la Biblioteca Nacional de París. Todavía nos mira a través de la cuestión "iqué es?" o mediante aquel interrogante extraño al filósofo: "¿qué es el latón?" Ciertamente extraño como el letrero de la peluquería de Don Víctor: "Afeitado, hoy 10 peniques, mañana gratis" (2015, pp. 98-99).

"En este juego — dice Benjamin— se trata sobre todo de pensar", puesto que "el campesino lo ve con frecuencia, el rey raras veces, y Dios nunca. ¿Qué es?" (218). ¿Sabemos qué es? Su interrogante contiene la clásica pregunta: "¿qué es?" ¿Benjamin lo sabe? El asunto requiere pensar o, por lo menos, hacer memoria, si así lo imaginamos.

El hecho que lo coloque de primero, indica el grado de dificultad que tiene el juego. Es un juego hermenéutico. Se le repasa lentamente, hasta que uno llega al final sin una respuesta para iniciar de nuevo: todo igual, sin igual y siempre igual de famosa desde 1889.

El tema tiene que ver con el ver. Ver es investigar. Investigar es preguntar y seguir preguntando, algo así como ver caminando a Wittgenstein en el estudio de Russell, en un ir y venir pensando en el asunto.

A este recorrer se le llama "pensar", "leer", "comprender". iQué difícil es el juego de entender a Benjamin: arqueólogo, historiador, crítico literario, traductor, teórico de la literatura, filósofo, todo un flâneur! Tiene la exigencia que se cumpla 
la condición de encontrar lo general, pues el acertijo exige hallar lo universal, lo coincidente que existe en una multiplicidad. En el fondo volvemos a Platón.

Quien tenga la respuesta, debe callar por ahora para desarrollar el ejercicio. ¿A quién podríamos recurrir? A nadie. Nos está vedado. Al nudo. Hay que ir al nudo para desatarlo, pues, la caja de Pandora no es sólo para los niños. Allí hay algo igual al campesino, al rey y al mismo Dios. "¿Qué es?" Nos acosa la pregunta.

La obra de Benjamin es un conjunto de fragmentos. El arte de coleccionarlos era su oficio: una especie de madurez del hombre que se va haciendo mayor al afinarse en el asunto no menor que le suena al oído en esa suerte de expectativa del corazón a la que hemos sido llamados.
A: ¿Le han investigado alguna vez?
$\mathrm{N}$ : iUy, santo Dios! iDos veces! Una vez que no tenía trabajo me investigué para ver si podía vivir del aire, y poco después fui investigado aquí porque había tomado prestados dos panecillos a un panadero sin decirle nada. Ah, y la tercera vez fui también aquí investigado porque me había encontrado una herradura.
A: ¿̇nvestigado por eso? ¿Es que ha perdido usted el juicio?
$\mathrm{N}$ : ¿Perdido yo el juicio? iSanto Dios! No tanto como usted o eso me parece. Me encontré una herradura en la calle $y$, cuando la miré bien en casa, vi que tenía un caballo (Benjamin, 2015, p. 94).

Los libros son regalos de los hombres; zapatos cómodos cuando están bien hechos o muebles bien acabados y finos en que la madera que reluce bajo la forma esconde el esplendor de quien la trabajó.

Los abro. iCuántas figuras y monstruos se liberan al instante! Demonios cruzan el camino. A veces van con el lector. Son los libros solitarios. Están erguidos en librerías y bibliotecas. Otros son leídos. En cualquier caso, esperan. Esperar en silencio es un secreto que tienen las cosas. No son como los árboles que todo el tiempo murmuran. Entonces brillan sus armaduras, sus fierros y colores. Sólo que de su puja surgen los héroes y los espíritus que comienzan a carcomernos y a no dejarnos ir con el agobio de que su llamado nos pertenece.

Los libros tienen una gran importancia en la vida de Benjamin, aunque no había nacido en una cuna de libreros, su don era coleccionarlos. Algunos pasaron de ser simple "cosa" a "objeto"; otros, con el tiempo, "la cosa en cuestión", para terminar en la mesa de trabajo como la "cosa investigada". Nunca fueron al taller del encuadernador; se quedaron en las manos del intérprete como «textos». El mismo asegura: "El escritor debiera acordarse de que la palabra "texto" — de tejido: textum — ha tenido ese nombre honroso" (1998, p. 153). 
Hay algo que aprender de Walter Benjamin. Adorno hablaba con predilección de "Los colores"; Hannah Arendt del "Jorobadito". Todos de ese libro escondido y sonsacado como es Infancia en Berlín hacia 1900.

Así, me parece que en este libro se ha quedado, en un instante, con un espíritu que va con uno y, que cuando se compra en una librería de viejo, ya no es uno, sino también otro que se une al que anda con uno por el camino. En estas, recordé cómo sentí la alegría de aquella muchacha que me vio entrar a la peluquería y quedó como el hijo desdichado de un encuentro porque no se sabe cuándo ni cómo llegan esas cosas como noticia trasmitida del destino; como fue también el caso de la introducción de Hegel en el círculo de Mallarmé: cuando se vio que la envoltura de unas papas calientes era un fragmento de la Estética de Hegel.

Para nosotros también nos tiene reservada una corta introducción con "Los colores" como su fragmento principal.

Los colores. En nuestro jardín había un pabellón abandonado amenazando ruina. Le tenía cariño por sus ventanas de cristales coloreados. Si pasaba la mano en su interior me iba transformando de cristal en cristal, tomando los colores del paisaje que se veía en las ventanas, ahora llameante, ahora polvoriento, ya ardiente, ya exuberante. Lo mismo me sucedía cuando pintaba en colores y se me abrían las cosas en su seno, tan pronto que las Ilenaba con una nube húmeda. Con las pompas de jabón ocurría algo parecido. Viajaba con ellas por la habitación metiéndome en el juego de los colores de los globos hasta que reventaban. Me perdía en los colores por lo alto del cielo, lo mismo que en una joya, en un libro; pues en todas partes los niños son su presa. En aquella época se podía comprar el chocolate en unos paquetitos, en los que cada una de las tabletas, dispuestas en forma de cruz, estaba envuelta en papel de estaño de diferentes colores. La pequeña obra de arte, sujetada por un rudo hilo de oro, resplandecía de verde y oro, azul y naranja, rojo y plata. Jamás se tocaban dos piezas del mismo envoltorio. Venciendo la barrera, los colores me asaltaron y aún siento la dulzura con la que entonces se empaparon mis ojos. Fue lo dulce del chocolate con el que esta dulzura iba a deshacérseme más en el corazón que en la boca. Pues antes de que sucumbiera a las tentaciones de la golosina, de golpe un sentido más elevado dentro de mí dejo atrás otro más bajo y me quedé embelesado (Benjamin, 1982, pp. 69-70).

Los colores, el texto de Walter Benjamin pertenece a Infancia en Berlín hacia 1900. Esta es una forma de enunciar por qué su tejido se encuentra en todas las partes de la obra de Benjamin. Se le topa como fragmento, como cita, como método. Los colores es un texto metodológico. Allí está contenido el método de trabajo, el partir de lo pequeño, de lo insignificante; en el fondo, de la vida, para encontrar en lo pequeño lo universal. Eso es Walter Benjamin, un pensador de lo pequeño como lo fue Edmund Husserl y Martin Heidegger. 
¿A qué se debe el aprecio que sintió Benjamin por Los colores? ¿Por qué Adorno reconoció que allí hay algo especial? ¿Qué método es este que ha empleado y que, supuestamente, está contenido en este texto y en toda la obra?

Cuando investigamos buscamos lo universal. ¿En dónde debe centrarse la atención cuando lo leemos? Es el texto central de Benjamin; de su comprensión depende la intelección de su obra. Encontramos allí lo coincidente, "la barrera". En el fondo, se trata de vencer un límite: "de golpe un sentido elevado dentro de mí", el salto.

Si es un tratado de método "en estado práctico", el método es la dialéctica, la fenomenología de Husserl o su propia hermenéutica. En tanto, lo sea, Los colores elabora la tematización al dilucidar su objeto desde diferentes ángulos, lleva adelante la variación libre de la imaginación al mostrar lo coincidente en lo distinto: colores, cristales, pompas de jabón, globos, envolturas; y propone una idea: "lo mismo sucedía cuando pintaba en colores y se me abrían las cosas en su seno" (Benjamin, 1982, p. 69).

El ver se centra en algo. A través de la mirada se filtra la luz de los cristales, de los globos, las pompas de jabón y las envolturas de celofán de lo coincidente: la colección, la repetición, la semejanza, lo fractal, la continua elaboración de lo mismo que desemboca en el conocimiento de uno mismo que se plasma en el símbolo: "venciendo un día la barrera, los colores me asaltaron y aún siento la dulzura con la que entonces se empaparon mis ojos". Pero, más allá de esto, queda pendiente, como si fuese el culmen de un diálogo de Platón, cuál es el sentido elevado dentro de mí y que deja atrás a otro más bajo para sentirse uno tan embelesado.

\section{Conclusión}

Es posible plantearnos otros problemas. Si el texto de Los colores es un buen discurso o, desde otro punto de vista, preguntarnos por el lugar que ocupa en la obra de Benjamin; desde su producción, su origen, condiciones, dificultades, ediciones, traducciones, su presencia en la correspondencia, su recepción en Iberoamérica y comentarios al respecto, por ejemplo, de Adorno, Hannah Arendt, Rafael Gutiérrez Girardot.

Desde el punto de vista hermenéutico, cuál es su pregunta, su sentido, la relación de las partes y el todo, su «punto medio» y extremos, sus relaciones con la vida, con el tiempo, con la escritura; es posible volver sobre él desde las apreciaciones críticas de Benjamin, y cuidado del mismo y como fue encomendado a sus corresponsales, lectores y comentaristas. 
Es posible preguntarnos muchas cosas sobre la obra de Benjamin para determinar qué materia se laboró en su taller, en su molino, en la biblioteca y cuáles fueron sus métodos e instrumentos de trabajo: «un Igual» es la respuesta a uno de los acertijos para los niños de Radio Benjamin $\varphi$

\section{REFERENCIAS}

Adorno, T. y Benjamin, W. (1998). Correspondencia (1928-1940). Madrid: Editorial Trotta.

Benjamin, W. (2015). Radio Benjamin. Madrid: Ediciones Akal.

Benjamin, W. (2012). El truco preferido de Satán. Madrid: Editorial Salto de Página

Benjamin, W. (2011). Diario de Moscú. Buenos Aires: Ediciones Godot Argentina.

Benjamin, W. (2010). El narrador. Santiago de Chile: Ediciones/metales pesados.

Benjamin, W. (2009). La dialéctica en suspenso. Fragmentos sobre la historia. Santiago de Chile: LOM Ediciones.

Benjamin, W. (2007). "Experiencia y pobreza". En Obras, libro /l / vol. 1. Madrid: Abada Editores.

Benjamin, W. (2004). Libro de los pasajes. Madrid: Ediciones Akal.

Benjamin, W. (1982). Infancia en Berlín hacia 1900. Madrid: Ediciones Alfaguara.

Benjamin, W. (1998). Iluminaciones I. Imaginación y sociedad. Madrid: Taurus.

Buck-Morss, S. (1995). Dialéctica de la mirada. Walter Benjamin y el proyecto de los Pasajes. Madrid: La balsa de la Medusa.

Gadamer, H. (1992). Verdad y método II. Salamanca: Ediciones Sígueme.

Marx, U. (2010). "Árbol del esmero. Benjamin como archivero". En Archivos de Walter Benjamin. Fotografías, textos y dibujos. Madrid: Círculo de Bellas Artes.

Nietzsche, F. (1992). Fragmentos póstumos. Bogotá: Norma.

Scholem, G. (2007). Walter Benjamin. Historia de una amistad. Barcelona: Debolsillo. 